\title{
Vascular permeability, vascular hyperpermeability and angiogenesis
}

\author{
Janice A. Nagy · Laura Benjamin · Huiyan Zeng • \\ Ann M. Dvorak · Harold F. Dvorak
}

Received: 16 January 2008/ Accepted: 27 January 2008/Published online: 22 February 2008

(C) The Author(s) 2008

\begin{abstract}
The vascular system has the critical function of supplying tissues with nutrients and clearing waste products. To accomplish these goals, the vasculature must be sufficiently permeable to allow the free, bidirectional passage of small molecules and gases and, to a lesser extent, of plasma proteins. Physiologists and many vascular biologists differ as to the definition of vascular permeability and the proper methodology for its measurement. We review these conflicting views, finding that both provide useful but complementary information. Vascular permeability by any measure is dramatically increased in acute and chronic inflammation, cancer, and wound healing. This hyperpermeability is mediated by acute or chronic exposure to vascular permeabilizing agents, particularly vascular permeability factor/vascular endothelial growth factor (VPF/ VEGF, VEGF-A). We demonstrate that three distinctly different types of vascular permeability can be distinguished, based on the different types of microvessels involved, the composition of the extravasate, and the
\end{abstract}

J. A. Nagy · L. Benjamin · H. Zeng · A. M. Dvorak ·

H. F. Dvorak $(\square)$

Department of Pathology, Beth Israel Deaconess Medical

Center, Harvard Medical School, Boston, MA 02215, USA

e-mail: hdvorak@bidmc.harvard.edu

J. A. Nagy

e-mail: jnagy@bidmc.harvard.edu

L. Benjamin

e-mail: lbenjami@bidmc.harvard.edu

H. Zeng

e-mail: hzeng@bidmc.harvard.edu

A. M. Dvorak

e-mail: advorak@bidmc.harvard.edu anatomic pathways by which molecules of different size cross-vascular endothelium. These are the basal vascular permeability (BVP) of normal tissues, the acute vascular hyperpermeability $(\mathrm{AVH})$ that occurs in response to a single, brief exposure to VEGF-A or other vascular permeabilizing agents, and the chronic vascular hyperpermeability $(\mathrm{CVH})$ that characterizes pathological angiogenesis. Finally, we list the numerous (at least 25) gene products that different authors have found to affect vascular permeability in variously engineered mice and classify them with respect to their participation, as far as possible, in BVP, AVH and CVH. Further work will be required to elucidate the signaling pathways by which each of these molecules, and others likely to be discovered, mediate the different types of vascular permeability.

Keywords Vascular permeability - Basal vascular permeability - Acute vascular hyperpermeability . Chronic vascular hyperpermeability · VEGF-A · VVO $\cdot$ Angiogenesis

\section{Introduction}

All cells require a continuing supply of nutrients and a means of clearing waste products. Single cells achieve these necessities by exchanging gases and small molecules directly with their environment by diffusion. However, vertebrates have solved the problems of nutrition and waste disposal by developing a vascular system that extends into all organs and tissues. While the vascular system of higher organisms is often described as "closed", it needs to be sufficiently "open" (i.e., "permeable") to allow the ready exchange of small molecules (gases, nutrients, waste products) with the tissues. Plasma proteins also need to 
cross the normal vascular barrier, at least in small amounts. Albumin, for example, transports fatty acids and vitamins and immunoglobulin antibodies are required for host defense.

Vascular permeability, then, is essential for the health of normal tissues and is also an important characteristic of many disease states in which it is greatly increased. Examples are acute inflammation and pathologies associated with angiogenesis such as tumors, wounds, and chronic inflammatory diseases [1-4]. However, there is considerable disagreement as to the meaning of the term vascular permeability and the methods by which it should be measured [5]. Also, permeability is an extremely complicated process that, however defined, is affected by many different variables. These include the intrinsic properties of the different types of microvessels involved (capillaries, venules, mother vessels(MV)); the size, shape, and charge of extravasating molecules; the anatomic pathways molecules take in crossing the endothelial cell barrier; the time course over which permeability is measured; and the animals and vascular beds that are being investigated. This review addresses these issues with the hope that investigators in different fields will be able to communicate more effectively with each other and better measure and evaluate the significance of vascular permeability in normal physiology and in various pathologic states. A closely related issue, that of the passage of inflammatory cells across the microvasculature, is discussed elsewhere [6-8].

\section{What is vascular permeability and how should it be measured?}

The physiologists' view of vascular permeability

Surprisingly, there is not good agreement as to what is meant by the term "vascular permeability" and from this it follows that there is no consensus about how vascular permeability should be measured. Over the last half-century eminent physiologists including Pappenheimer, Landis, Starling, Renkin, Michel, Curry, Rippe, and Bates have investigated the mechanisms by which plasma and its solutes cross the vascular barrier [5, 9-13]. They recognized that capillaries were the vascular segment involved in molecular exchange in normal tissues and that gases, water, and other small molecules crossed the capillary endothelial cell barrier freely whereas the passage of larger molecules such as plasma proteins was tightly restricted. Physiologists have commonly regarded capillary endothelium as a passive barrier, a thin, cellophane-like membrane that is punctuated by large numbers of small pores and lesser numbers of large pores. They postulated that the numerous small pores allowed the ready passage of small molecules and that the lesser number of large pores allowed limited extravasation of plasma proteins. With these assumptions in mind they developed elegant methods for investigating the flux of water and of plasma solutes across individual cannulated microvessels. They developed equations to calculate the three parameters that determine permeability, namely, hydraulic conductivity, reflection coefficient, and diffusion. Diffusion is the most important of these for the exchange of small molecules and is driven by the molecular concentration gradient across vascular endothelium as determined by the Fick equation:

$J s=D^{A} / T(C v-C i)$

where $J_{s}$ is the diffusion rate (e.g., $\mathrm{ml} / \mathrm{s}$ ) of a particular solute; $D$ is the diffusion coefficient for that solute; $A$ is surface area available for exchange; $T$ is the thickness of the capillary; and $C_{v}-C_{i}$ is the difference in solute concentration between the plasma and the interstitial fluid.

The value of $D$ in the Fick equation depends heavily on molecular size; for example, the diffusion of albumin across the vasculature is estimated to be $\sim 1,000$-fold less than that of water $[11,12]$. As a result, filtration is much more important than diffusion for the flux of large molecules such as plasma proteins and is determined by the Starling equation:

$J v=L p A[(P v-P i)-\sigma(\pi v-\pi i)]$

where $J_{v}$ is filtration rate (e.g., $\left.\mathrm{ml} / \mathrm{s}\right) ; L_{P}$ is hydraulic conductivity or the filtration coefficient, a property of the capillary wall and a measure of capillary permeability to water; $A$ is surface area available for molecular exchange; $P_{v}-P_{i}$ and $\pi_{v}-\pi_{i}$ are, respectively, the hydrostatic and osmotic pressure differences between the plasma and the interstitium; and $\sigma$ is the osmotic reflection or solvent-drag reflection coefficient. $\sigma$ varies in different tissues from 0 to 1 and tissues such as skin with high values (e.g., 0.9) permit little plasma-protein escape. Further details concerning the diffusion and Starling equations can be found in standard textbooks of Physiology and in several excellent reviews [12-16].

\section{Permeability as understood by vascular biologists}

In contrast to physiologists, vascular biologists have used the term vascular permeability in a less restrictive sense. Rather than being concerned with the permeability of a single cannulated microvessel, they have sought to measure the net amount of a solute, typically a macromolecule such as plasma albumin, that has crossed a vascular bed and accumulated in the interstitium in response to a vascular permeabilizing agent or at a site of pathological angiogenesis. Generally speaking, the vessels involved are not of 


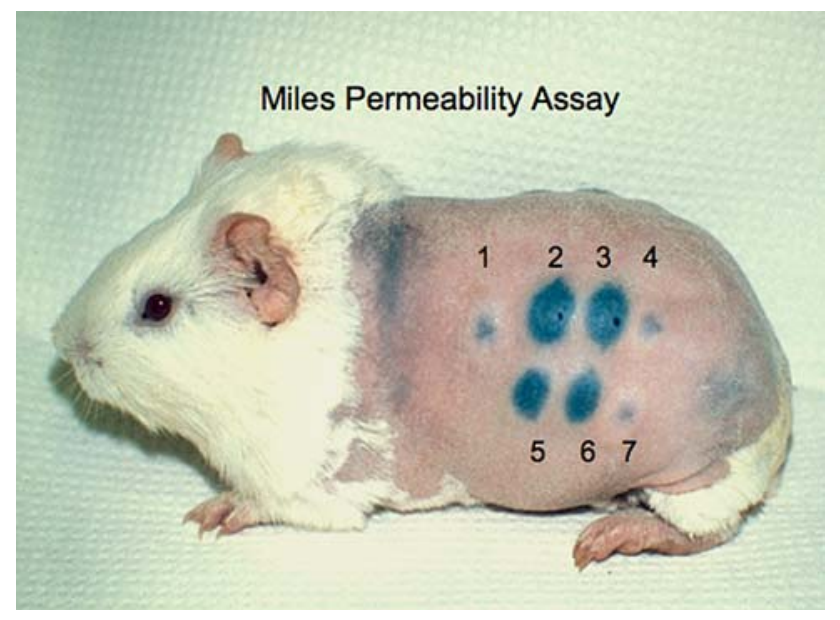

Fig. 1 Miles permeability assay. Various test substances were injected intradermally into the shaved and depilated flank skin of a Hartley guinea pig, followed immediately by an intravenous injection of Evan's blue dye. Animal was photographed 30 min later. Injected materials were as follows: 1, Neutralizing antibody against VEGF-A; 2 and 5, ascites tumor-associated VEGF-A; 3 and 6, ascites tumor associated VEGF-A plus control immunoglobulin; 4 and 7, ascites tumor-associated VEGF-A plus specific VEGF-A neutralizing antibody. Reproduced from [93]

a single type, and the measurements made combine together all of the factors, both intrinsic properties of the blood vessels as well as extrinsic properties such as blood flow, that regulate extravasation.

To obtain this type of information, they have generally used the Miles assay or one of its variants [17-19]. Typically, a dye such as Evan's blue that binds noncovalently to albumin is injected intravenously and its accumulation is measured at some later time at a skin test site (Fig. 1), in a tumor, or in other tissues of interest. Permeability is defined as the amount of albumin-dye complex that is present at some time (often $30 \mathrm{~min}$ ) after Evan's blue injection. The intensity of local bluing observed visually provides sufficient information for some purposes. For example, local bluing in guinea pig skin was used to evaluate column fractions in the original purification of vascular permeability factor/vascular endothelial growth factor (VPF/ VEGF, VEGF-A) [19]. However, quantitative measurements can be made by extracting the dye from tissues and measuring it spectrophotometrically [20]. A limitation of the Miles assay, whether permeability is assessed visually or by quantitative measurement, is that it does not distinguish between dye that has extravasated from that present within the vasculature. However, serious error does not result when intravascular volumes are small relative to the amounts of dye that have leaked, for example, at skin test sites injected with column fractions containing different amounts of VPF/VEGF. Another limitation is that the Miles assay measures net accumulation of dye-albumin complex over a period of time and return of extravasated molecules to the circulation, either by way of capillaries or lymphatics, is not considered. Despite these limitations the Miles assay has provided much useful information.

However, in tumors and in other examples of pathological angiogenesis, the vasculature undergoes dramatic changes and is not comparable to that of adjacent normal control tissues. In such instances it is important to measure both the content of tracer within blood vessels and that which has extravasated. This can be accomplished using a dual isotope approach [20-22]. Operationally, ${ }^{125}$ I-albumin is injected i.v. into a mouse at time zero. After $25 \mathrm{~min}$, a second i.v. injection is administered, this time of ${ }^{131} \mathrm{I}-$ albumin. After $5 \mathrm{~min}$, at time $30 \mathrm{~min}$, blood is collected, animals are euthanized and tissues of interest are harvested, weighed, and subjected to gamma counting. The following equations are used to calculate intravascular plasma volume $\left(V_{p}\right)$ and the albumin leakage rate $(L R)$ :

$A_{131}=C_{p 131} * V_{p}+L R * C_{p 131} * 5$

$A_{125}=C_{p 125} * V_{p}+L R * C_{p 125} * 30$

$L R=1 / 25 *\left(A_{125} / C_{p 125}-A_{131} / C_{p 131}\right)$

$V p=1 / 5 *\left(6 * A_{131} / C_{p 131}-A_{125} / C_{p 125}\right)$

$A=C_{p} * V p+L R * C_{p} * t$

where $A$ is total tissue radioactivity ( $\mu \mathrm{Ci} / \mathrm{g}$ ) of ${ }^{125} \mathrm{I}$-albumin or ${ }^{131} \mathrm{I}$-albumin; $C_{p}$ is concentration of radioactive tracer in plasma $(\mu \mathrm{Ci} / \mu \mathrm{l}) ; V_{p}$ is volume of plasma in tissue $(\mu \mathrm{l} / \mathrm{g})$; $L R$ is the leakage rate from plasma into tissue expressed as $\mu \mathrm{l} / \mathrm{min}-\mathrm{g}$ and is equivalent to the permeability-surface area product; and $t$ is time elapsed since injection of tracer (min).

An underlying assumption of this method is that even in the case of highly leaky blood vessels only negligible amounts of ${ }^{131} \mathrm{I}$-albumin will have had time to extravasate at $5 \mathrm{~min}$ after injection. Therefore, the ${ }^{131} \mathrm{I}$-albumin value at 5 min provides a quantitative measure of intravascular volume whereas the ${ }^{125} \mathrm{I}$-albumin value provides a measure of the sum of both intravascular and extravascular albumin. Extravasated albumin (i.e., the volume of plasma extravasated in $25 \mathrm{~min}$ ) can then be determined by subtracting the $5 \mathrm{~min}$ value from the $30 \mathrm{~min}$ value. This method has the disadvantages of using a strong, short-lived gamma emitter $\left({ }^{131} \mathrm{I}\right)$ and of not permitting visual inspection of tracer leakage as when Evan's blue dye is used as tracer. To circumvent these limitations we recently modified the method by substituting Evan's blue dye (hence plasma albumin) for the first tracer (30 min time point) and using ${ }^{125}$ I-albumin for the second ( 5 min time point). 
In vitro permeability assays or in vivo veritas?

The assays described above measure permeability in living animals. However, a number of groups have used in vitro assays to measure the flux of small or large molecules across lawns of confluent endothelial cells cultured on membrane filters in transwell chambers [5, 10, 23-26]. These assays are appealing in that they are relatively easy to perform and avoid the complexities of studies in living animals. However, in our view they suffer from severe limitations. Confluent-cultured endothelial cell monolayers, whether isolated from large or small vessels, are generally leakier than the normal blood vessel wall in vivo, perhaps because pericytes or smooth muscle cells that normally modify endothelial cell behavior are missing. Also, cultured endothelial cells generally have relatively few cytoplasmic vesicles and vacuoles, structures which are numerous in these same cells in vivo and provide the means by which solutes, and especially proteins, cross capillary and venular endothelium in vivo. Attempts to restore these vesicles have only been achieved in cultured endothelium under specialized conditions that are not easily amenable to permeability assays [27, 28]. Cultured endothelial cells are extremely flattened cells that do not resemble, for example, the cuboidal venular endothelium that is responsive to permeability agents such as VEGF-A or histamine in vivo. Finally, the kinetics of leakage in response to agents such as VEGF-A differ markedly in vivo and in cultured endothelium. In vivo, leakage in response to a single exposure to VEGF-A begins within a minute and is largely complete by $\sim 30 \mathrm{~min}$. However, increased permeability develops much more slowly in cultured endothelium and often peaks over a period of hours, suggesting that the permeability observed may reflect, at least in part, a loosening of intercellular connections as endothelial cell are stimulated to migrate by VEGF-A. In sum, current in vitro assays do not mimic the basal vascular permeability or acute vascular hyperpermeability observed in vivo, but may provide a model for measuring the chronic vascular hyperpermeability characteristic of pathological angiogenesis as found in tumors, healing wounds, and chronic inflammation (see below).

Basal vascular permeability (BVP), acute vascular hyperpermeability $(\mathrm{AVH})$, and the chronic vascular hyperpermeability $(\mathrm{CVH})$ of pathological angiogenesis

As was already noted, low levels of vascular permeability to plasma proteins are essential for the health of normal tissues and these levels may vary considerably at different times in different organs and tissues in response to different physiological stimuli, e.g., exercise. However, it is important to distinguish between the basal permeability levels of normal tissues and the greatly increased levels of plasma protein extravasation that occur in pathology. These hyperpermeable states may be acute or chronic and differ from each other and from basal levels of permeability with respect to the vessels that leak, the composition of the extravasate, and the anatomic pathways that solutes follow in crossing vascular endothelium. Each of the three types of permeability will now be discussed in turn.

\section{Basal vascular permeability (BVP)}

Molecular exchange in normal tissues takes place primarily in capillaries. Indeed, it may be stated that the primary function of several major organs (heart, lungs, kidneys) and of larger blood vessels (arteries, arterioles, veins, venules) is to supply the capillaries, and thus the tissues, with nutrients and to clear waste products. The molecules exchanged consist largely of gases $\left(\mathrm{O}_{2}\right.$ and $\left.\mathrm{CO}_{2}\right)$, water, small molecules such as salts and sugars, and only small amounts of plasma proteins. The process is driven largely by diffusion. The extent of BVP varies considerably in different normal tissues and is subject to substantial change in response to changes in hydrostatic pressure, opening of closed vessels, surface area available for exchange, blood flow, etc.

How do plasma water and solutes of different size traverse capillaries? As noted above, physiologists have likened capillary endothelium to a thin, passive barrier penetrated by pores of varying size. These putative pores were recognized to be too small to be visualized by light microscopy. Therefore, there was great excitement that electron microscopy, as it became available in the 1950s, would be able to visualize the pores. But these expectations were not immediately realized. No "pores" as such were found in normal capillary endothelium. Nonetheless, it was not difficult to explain the transport pathways followed by small molecules. Water and lipophilic solutes (e.g., gases such as $\mathrm{O}_{2}$ and $\mathrm{CO}_{2}$ ) are able to diffuse through endothelial cells; they also pass readily through inter-endothelial cell junctions and through endothelial fenestrae. ${ }^{1}$ Small lipophilic molecules can also dissolve in endothelial cell membranes and so pass from the vascular lumen to the interstitium. However, none of these routes provided a satisfactory explanation for the passage of large molecules. Small proteins such as horseradish peroxidase can pass

\footnotetext{
${ }^{1}$ Fenestrae are greatly thinned (70-150-nm diameter) zones of microvascular endothelium that can be induced by VEGF-A [60]. They are found in small numbers in many types of vascular endothelium and are especially numerous in specialized vascular beds that supply tissues that secrete protein hormones. They are induced in other types of vascular endothelium by VEGF-A[60]. Fenestrae are closed by a thin diaphragm, similar structurally to the diaphragms closing the stomata found in caveolae and VVOs [29, 34].
} 
through inter-endothelial cell junctions, but do so at rates that are much slower than their entry into tissues [29, 30]. Further, at a MW of $44 \mathrm{kD}, \mathrm{HRP}$ is significantly smaller than the smallest plasma proteins such as albumin (MW $69 \mathrm{kD}$ ) and therefore does not provide an ideal model for plasma-protein leakage.

A solution to the problem of plasma-protein extravasation into normal tissues was offered by George Palade who observed that capillary endothelium contained large numbers of small ( $\sim 70-\mathrm{nm}$ diameter) vesicles [31-33]. He named these plasmalemmal vesicles and they are now more commonly referred to as caveolae (Fig. 2a, b). The majority of caveolae are found connected to the luminal and abluminal plasma membranes by means of stomata that are generally closed by thin diaphragms. Little is known about the composition of these diaphragms other than that they contain a unique protein, $\mathrm{PV}-1$, and likely sulfated proteoglycans [34]. Palade postulated that caveolae shuttled across capillary endothelium carrying cargoes of plasma fluid and proteins and this was subsequently demonstrated experimentally with tracers (reviewed in [29]). Thus it seemed that the large pores postulated by physiologists were not pores at all but shuttling caveolae and that transport of large molecules across capillaries was anything but passive. This concept stood the test of time until quite recently when it was found that caveolin-1 null mice that
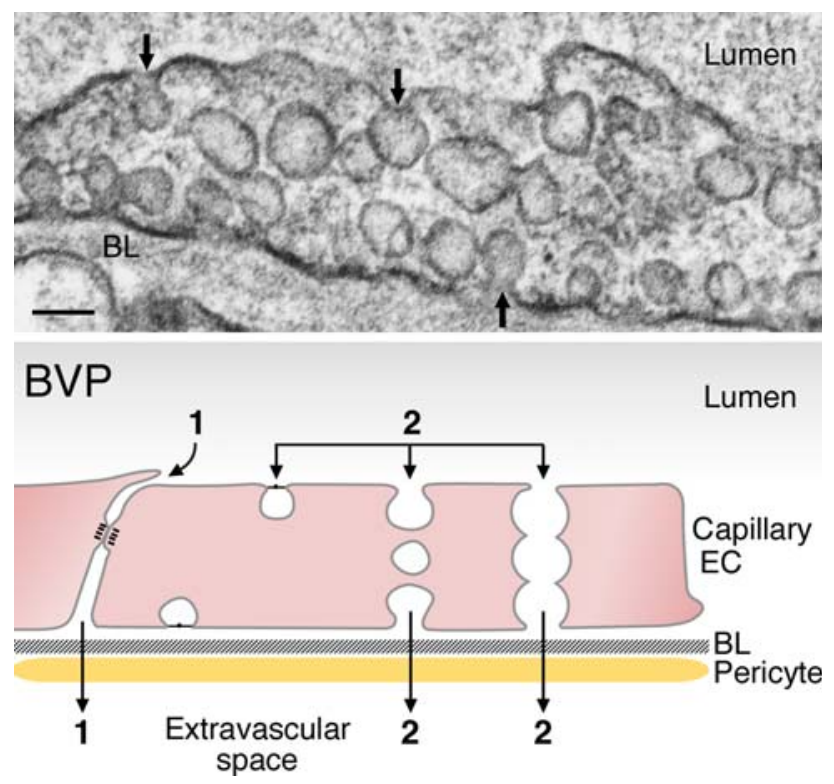

Fig. 2 Upper panel: Electron micrograph illustrating a typical capillary endothelial cell with numerous caveolae. Many of these are connected to the luminal or abluminal plasma membranes (arrows), whereas others are in the cytoplasm. L, lumen scale bar, $100 \mathrm{~nm}$. Lower panel: Schematic diagram illustrating pathways by which molecules can cross the capillary barrier. (1) intercellular cleft; (2) caveolae that may shuttle across the capillary or form a chain of vesicles that connect the lumen and albumen. BL, basal lamina lack capillary endothelial caveolae altogether actually exhibit increased permeability to albumin [35, 36]. More will be said about this later.

\section{Acute vascular hyperpermeability $(A V H)$}

A rapid increase in vascular permeability occurs when the microvasculature is exposed acutely to any of a number of vascular permeabilizing factors, e.g., VEGF-A, histamine, serotonin, PAF, etc. Some of these agents (e.g., histamine, serotonin, VEGF-A) are normally stored in tissue mast cells [37-39] and so may be released by agents that cause mast cell degranulation, e.g., allergy, insect bites, etc. Single exposure to any of these permeability factors results in a rapid but self-limited (complete by $20-30 \mathrm{~min}$ ) influx of plasma into the tissues. Not only is the quantity of extravasated fluid greatly increased above that found in BVP but its composition is greatly changed. As already noted, the fluid passing from the circulation into normal tissues under basal conditions is a plasma filtrate, i.e., a fluid consisting largely of water and small solutes but containing very little plasma protein. However, the fluid that extravasates in $\mathrm{AVH}$ is rich in plasma proteins, approaching the levels found in plasma, and is referred to as an exudate. Among the plasma proteins that extravasate are fibrinogen and various members of the blood clotting cascade. When these come into contact with tissue factor, a protein that is normally expressed by many interstitial cells, the clotting system is activated and the exudate clots to deposit fibrin [40, 41]. Fibrin forms a gel that traps water and other solutes, restraining their clearance by lymphatics or capillaries and resulting in tissue swelling (edema). Fibrin in tissues has other functions that are discussed below. However, as long as the permeability stimulus is not continuous, the deposited fibrin is rapidly degraded without further consequences.

AVH also differs from BVP in that, as Guido Majno demonstrated, the vascular leakage takes place not from capillaries but from post-capillary venules, highly specific vessels just downstream of capillaries [42, 43]. Whereas capillaries have a flattened endothelium, venules are lined by a much taller, cuboidal endothelium. Majno also proposed a mechanism of protein leakage, namely that histamine and other vascular permeabilizing agents induced endothelial cells to contract and pull apart to form intercellular (paracellular) gaps of sufficient size to permit plasma-protein extravasation.

More recently, a structure was discovered in venular endothelium, the vesiculo-vacuolar organelle (VVO), that offers an alternative, trans-endothelial cell route for plasma extravasation in response to permeability factors [44-48]. VVOs are grape-like clusters comprised of hundreds of uncoated, cytoplasmic vesicles and vacuoles that together 
form an organelle that traverses venular endothelial cytoplasm from lumen to albumen (Figs. 3(a, b), 4a). VVOs often extend to inter-endothelial cell interfaces and their individual vesicles (unlike caveolae) commonly open to the inter-endothelial cell cleft. The vesicles and vacuoles comprising VVOs vary in size from those the size of caveolae to vacuoles with volumes as much as 10 -fold larger [49]. These vesicles and vacuoles are linked to each other and to the luminal and abluminal plasma membranes by stomata that are normally closed by thin diaphragms that appear similar to those found in caveolae. We conjectured some years ago that VVOs formed from the linking together of individual caveolae and that larger vesicles and vacuoles resulted from the fusion of two or more caveolae-sized vesicles [49]. Evidence for this was that the smallest VVO vesicles were indistinguishable structurally from caveolae and larger vesicles and vacuoles have volumes that do not fall on a continuum but have a modal distribution, i.e., occur as multiples of the volume of caveolae, the unit vesicle, up to 10-mers. However, VVO vesicles and vacuoles only stain irregularly for caveolin (unpublished data), a protein that is demonstrable by electron microscopic immunocytochemistry in nearly all plasma membrane-connected caveolae. Also, whereas the capillaries in caveolin-1 null mice lack caveolae altogether [36], VVOs are present in normal numbers in the venular endothelium of these mice (unpublished data). Whether VVOs somehow take the place of caveolae in caveolin-1 null mice and thereby contribute to the increased permeability observed in these animals needs to be investigated.

Although very little is known about the mechanisms of VVO function, it is clear that, upon exposure to histamine, VEGF-A, etc., macromolecular tracers such as ferritin pass through a sequence of inter-connected VVO vesicles and vacuoles from the vascular lumen to the albumen (Fig. 4b) It seems that vascular permeability inducing agents cause the diaphragms interconnecting vesicles and vacuoles to open, thereby providing a transcellular pathway for plasma and plasma-protein extravasation. The underlying mechanism could be mechanical, as was the endothelial cell contraction mechanism originally postulated by Majno [43]. If so, the actin-myosin contractions induced by

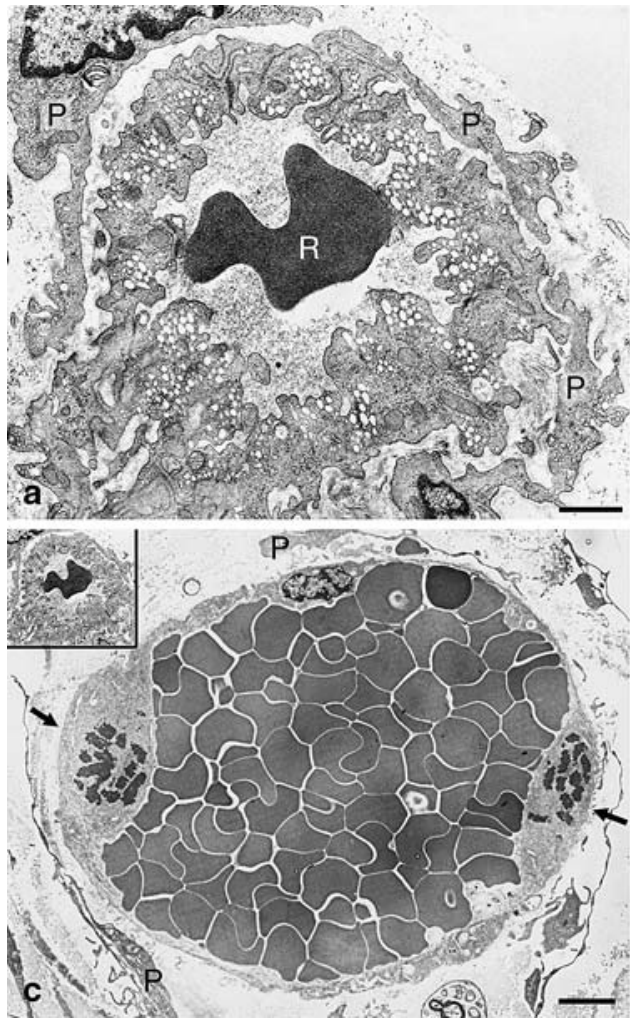

Fig. 3 Transmission electron micrographs of venules in normal mouse ear skin (a, b) and of a mother vessel (c, d) 3 days after local injection of Ad-VEGF-A ${ }^{164}$. (a, b) Typical normal venules lined by cuboidal endothelium. The cytoplasm contains prominent vesiculovacuolar organelles (VVOs) and is enveloped by a complete coating of pericytes $(\mathrm{P})$. R, red blood cell. (c, d) MV are greatly enlarged vessels that are characterized by extensive endothelial cell thinning; striking reduction in VVOs and other cytoplasmic vesicles; prominent

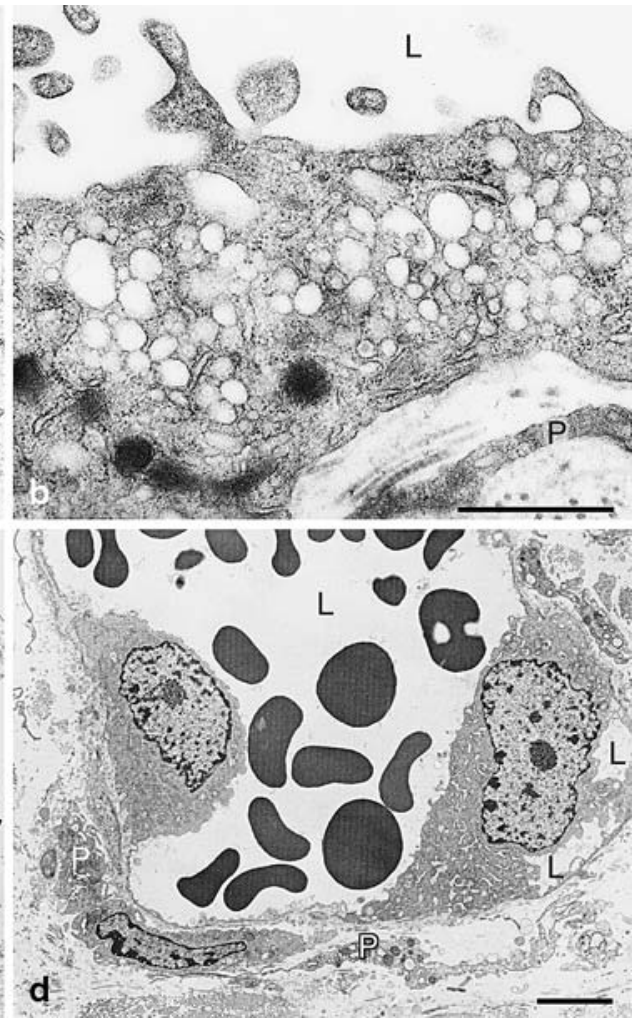

nuclei that project into the vascular lumen; frequent mitotic figures (arrows, c); endothelial cell bridging with the formation of multiple lumens (L, d); and pericyte (P) detachment in (c). The mother vessel lumen (c) is packed with red blood cells, indicative of extensive plasma extravasation. Inset. The normal venule depicted in $\mathbf{a}$ is reproduced in $\mathbf{c}$ at the same magnification as the mother vessel to illustrate differences in relative size of normal venules and MV. Scale bars: (a, b) $1 \mu \mathrm{m}$; (c, d) $5 \mu \mathrm{m}$ 


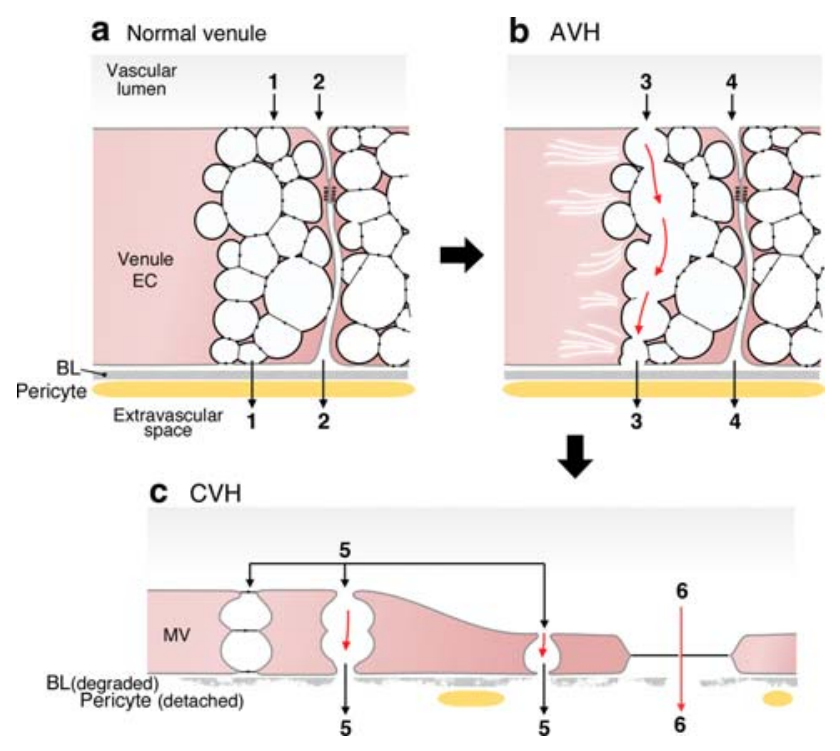

Fig. 4 (a) Schematic diagram of a normal venule comprised of cuboidal endothelium with prominent VVOs and closed interendothelial cell junctions. Note that some VVO vesicles attach to the intercellular cleft below the tight and adherens junction zones. 1 and 2 indicate potential pathways for transcellular (VVO) and intercellular (paracellular) plasma extravasation, respectively. Basal lamina (BL) is intact and the endothelium is completely covered by pericytes. (b) AVH. Acute exposure to VEGF-A causes VVO to open, allowing transcellular passage of plasma contents, possibly by mechanical pulling apart of stomatal diaphragms (3). Others have suggested that fluid extravasation takes place through an opening of intercellular junctions (4, here shown closed). BL and pericyte coverage are as in (a). (c) CVH. Prolonged VEGF-A stimulation causes venular endothelium to transform into MV, greatly thinned, hyperpermeable cells with fewer VVOs and VVO vesicles/vacuoles, degraded BL, and extensive loss of pericyte coverage. Plasma may extravasate either through residual VVO vesicles (5) or through fenestrae (6)

permeability factors would act to pull apart the diaphragms linking adjacent VVO vesicles and vacuoles, resulting in a transcellular rather than an inter-endothelial cell (paracellular) route for plasma extravasation. Determining whether solutes cross venular endothelium by inter-endothelial cell or transcellular (by VVOs) pathways is difficult because of the tortuosity of inter-endothelial cell borders and the proximity of VVOs to these borders. Three-dimensional (3D) reconstructions at the electron microscopic level have demonstrated that many of the openings induced in venular endothelium by permeability factors are in fact transendothelial cell pores [48-50].

\section{Chronic vascular hyperpermeability $(\mathrm{CVH})$}

Whereas acute exposure to VEGF-A results in immediate but self-limited hyperpermeability of normal venules, chronic exposure results in profound changes in venular structure and function that lead to the chronic hyperpermeability of pathological angiogenesis ${ }^{2}$ as found in tumors, healing wounds, and chronic inflammatory diseases such as rheumatoid arthritis, psoriasis, cellular immunity, etc. $[1,2,51]$. As in $\mathrm{AVH}$, the fluid that extravasates is an exudate that approaches the overall composition of plasma. In tumors fluid accumulation is generally associated with increased interstitial pressure [52]; this increased pressure results from persistent vascular hyperpermeability, clotting of the exudate with deposition of a fluid-trapping fibrin gel, inadequate lymphatic drainage, and the restraints imposed by surrounding tissues that together limit fluid dissipation. However, these restraints are nearly absent when tumors grow in or around body cavities such as the peritoneum where massive amounts of ascites fluid (many liters) can accumulate.

In contrast to BVP and $\mathrm{AVH}$, fluid leakage in $\mathrm{CVH}$ does not take place from any type of normal blood vessel. Instead, whether in tumors or wounds, the blood vessels that leak are newly formed, highly abnormal angiogenic blood vessels; these are primarily mother vessels (MV), and also, to a lesser extent, glomeruloid microvascular proliferations (GMP) that form from MV [20, 53-57] (Figs. 3c, d, 4c, 5). Mother Vessels are greatly enlarged sinusoids that arise from preexisting normal venules by a process that involves pericyte detachment, vascular basal lamina degradation, and a 4-5-fold increase in lumen size that is accompanied by extensive endothelial cell thinning. Poiseuille's law indicates that blood flow is proportional to the fourth power of the vascular radius. Nonetheless, MV exhibit sluggish blood flow because of their hyperpermeability to plasma which results in a striking increase in hematocrit (Fig. 3c).

As expected, the protein-rich exudates in $\mathrm{CVH}$ interact with tissue factor to trigger the clotting system and deposit fibrin [40, 41]. Tissue factor is expressed on many tumor cells as well as host interstitial cells and is induced in endothelial cells by VEGF-A [58]. In addition to its fluid trapping properties, fibrin also has a number of other properties when it persists over time as in tumors and healing wounds. It provides a pro-angiogenic provisional stroma that induces and is later replaced by the ingrowth of new blood vessels and fibroblasts and the laying down of mature fibro-vascular stroma [2, 17, 59]. Fibrin interacts with integrins expressed by multiple cell types and so supports the migration of tumor cells as well as host mesenchymal cells (endothelial cells, pericytes, fibroblasts) and inflammatory cells (neutrophils, monocytes). Fibrin

\footnotetext{
${ }^{2}$ Although careful measurements have not been made, it is unlikely that extensive vascular permeability accompanies the angiogenesis of normal development. At least in later stages of embryonic growth and post-natally, the developing blood vessels exhibit the structure of normal adult vessels and do not resemble the chronically permeable $\mathrm{MV}$ found in pathological angiogenesis.
} 


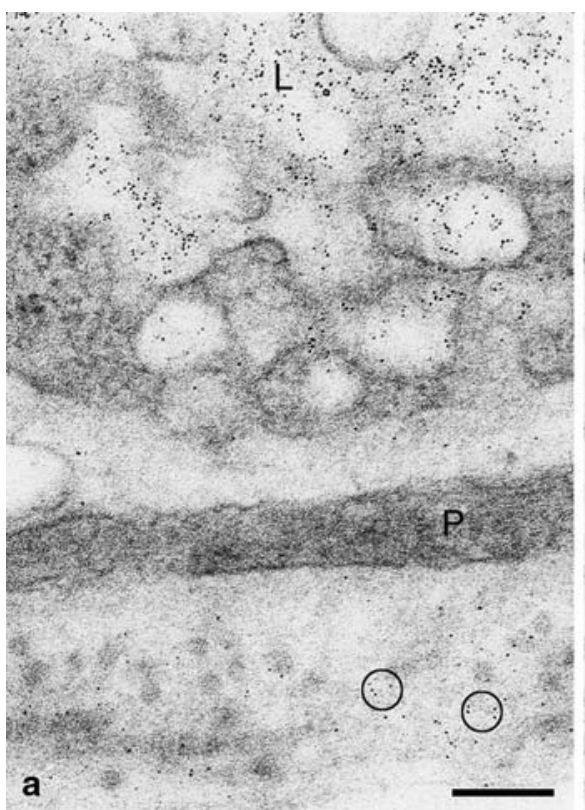

Fig. 5 Electron micrographs of portions of a MV (a) and a GMP (b) at 5 and 10 days following local injection of Ad-VEGF-A ${ }^{164}$ into nude mouse ears and $30 \mathrm{~min}$ after i.v. injection of ferritin tracer. (a) MV endothelium is greatly thinned and spanned by no more than 1-3 vesicles/vacuoles. Ferritin (dark-black particles) fill vascular lumens (L), are present in VVO vesicles/vacuoles, and have extravasated into

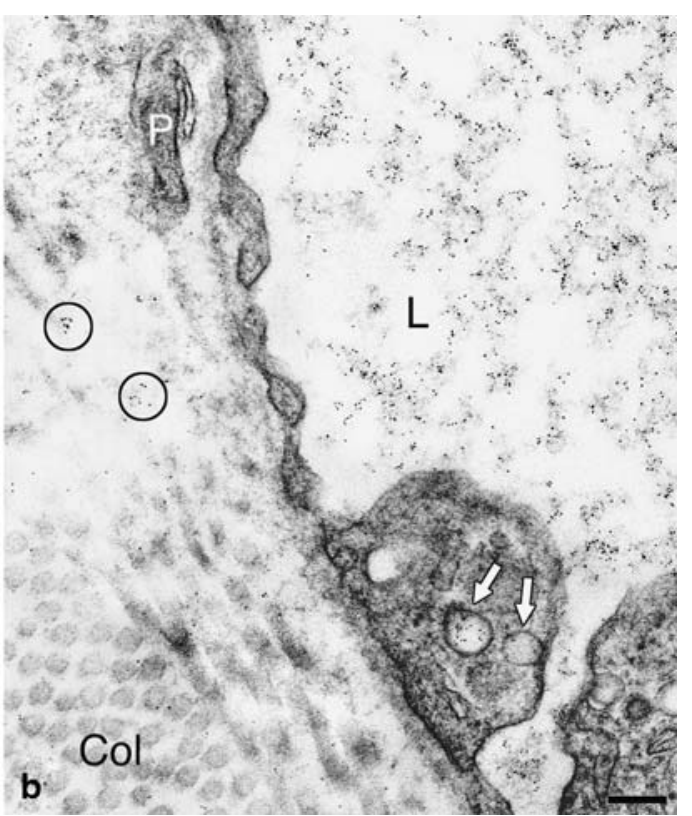

the extravascular space (some encircled). (b) GMP with extensively thinned and fenestrated endothelium. Ferritin is present in lumen, occasional residual cytoplasmic vesicles (white arrows) and in extravascular space, some encircled. p, pericyte. Scale bars, $200 \mathrm{~nm}$. Reprinted in revised form from [20]

Table 1 Decreased $(\Downarrow \Downarrow)$, increased $(\nabla \nabla)$, or unchanged $(\Leftrightarrow \Leftrightarrow)$ basal, acute, or chronic vascular permeability in various engineered mice

\begin{tabular}{|c|c|c|}
\hline \multirow[t]{3}{*}{ Basal } & $\Downarrow \Downarrow$ & $? ?$ \\
\hline & $\Uparrow \Uparrow$ & $\begin{array}{l}\text { Caveolin-1 null [36]; [35]; eNOS null [66]; endothelial cell specific myrAkt TG [67]; P1GF K14 TG } \\
\text { [68]; VEGF-A }{ }^{164} \text { K14 TG [69]; VEGF-A }{ }^{120} \text { K14 TG [70]; collagen XVIII null [71] }\end{array}$ \\
\hline & $\Leftrightarrow \Leftrightarrow$ & $\begin{array}{l}\text { eNOS null [72]; Akt-1 null }[64,73,74]\} ; \text { TSP-1 K14 TG [75]; TSP-2 null [76]; } \beta 3 \text { integrin null } \\
\text { [77]; HIF- } 1 \alpha \text { K14 TG [78]; }\end{array}$ \\
\hline \multirow[t]{3}{*}{ Acute, VEGF-A-mediated } & $\Downarrow \Downarrow$ & $\begin{array}{l}\text { eNOS null [79]; endothelial cell specific caveolin-1 TG [80]; Akt-1 null [73]; Src and } \\
\text { Yes null [81]; angiotensin II type } 1 \text { receptor null [82]; PlGF null [83, 84]; Ang-1 K14 TG } \\
\text { [69]; sNRP-1 K14 TG [85]; ESAM null [86]; } \beta 5 \text { integrin null [87] }\end{array}$ \\
\hline & $\Uparrow \Uparrow$ & $\beta 3$ integrin null [77] \\
\hline & $\Leftrightarrow \Leftrightarrow$ & $\begin{array}{l}\text { iNOS null [79]; endothelial specific myrAkt endothelial cell TG [67]; Fyn null [81]; } \\
\text { collagen XVIII null [71] }\end{array}$ \\
\hline \multirow[t]{2}{*}{ Chronic, VEGF-A/tumor mediated } & $\Downarrow \Downarrow$ & $\begin{array}{l}\text { eNOS null [79]; caveolin-1 null [88, 89]; endothelial cell-specific cav-1 TG [80]; } \\
\text { Akt-1 null [73]; PIGF null [84] }\end{array}$ \\
\hline & $\Uparrow \Uparrow$ & $\beta 3$ integrin null and $\beta 3 / \beta 5$ integrin double null [90]; caveolin-1 null $[91,92]$ \\
\hline
\end{tabular}

also sequesters growth factors, protecting them from degradation, and induces the expression of proangiogenic molecules such as IL-8 and tissue factor. Fragment E, a fibrin breakdown product, is directly pro-angiogenic (reviewed in [1, 58]).

Macromolecules such as ferritin extravasate from MV and GMP largely by a transcellular route [20]. As noted above, MV develop from normal venules by a process that involves extensive vascular enlargement with consequent endothelial cell thinning, processes that are thought to be facilitated, at least in part, by a transfer of VVO membranes to the plasma membrane [20]. As a result, MV, as well as the GMP that derive from MV, contain many fewer and less complex VVOs than normal venular endothelium. However, the path length for molecular extravasation is greatly shortened as tracers such as ferritin need to pass through only a few, often only one or two, vesicles or vacuoles to reach the ablumen (Fig. 3(c, d), 4c, 5b). Macromolecules also extravasate through fenestrae that are present in both MV and GMP [49] (Figs. 4c, 5c). Pores of the type that have been described in AVH have also been found in the endothelial cells of blood vessels 
supplying tumors $[43,46,60]$ (Fig. 4c). As noted earlier, such openings have often been called intercellular. However, careful 3D reconstructions of serial electron microscopic sections have shown that many pores induced by vascular permeabilizing agents are in fact transcellular pores that pass through endothelial cell cytoplasm $[48,50]$.

Molecular and genetic events that regulate vascular permeability

This review has shown that vascular permeability, far from being a single, well-defined entity, is instead an extremely complex process that in different settings, involves distinctly different types of blood vessels and makes use of different anatomic pathways. Further, whereas the fluid extravasating in $\mathrm{BVH}$ is a plasma filtrate consisting almost entirely of water and small solutes, that extravasating in $\mathrm{AVH}$ and $\mathrm{CVH}$, is a protein-rich exudate. Agents such as VEGF-A have long been known to induce AVH and CVH, but, apart from hemodynamic factors, much less is known about the molecular events that are responsible for the normal permeability of BVP. Even less is known about the molecules that are involved in regulating permeability, though this is changing rapidly. In Table 1 we have listed as many of the published gene products of which we are aware that have been implicated in vascular permeability. Some of these molecules have long been known to have roles in permeability whereas others have only recently been recognized to have such a role. However, the signaling pathways by which even such well-studied molecules as eNOS and caveolin-1 act to induce permeability are poorly understood. Almost nothing is known about the molecular mechanisms that regulate such critical events as caveolar shuttling, the opening of VVO diaphragms, the formation of fenestrae, changes in endothelial cell junctions, etc. [61-63]. We have attempted to catalog the molecules in Table 1, as far as is possible with existing knowledge, under the headings of BVP, AVH, and CVH. Some of these molecules are clearly involved in all three types of permeability whereas others apparently are not. The molecular mechanisms that govern each of the different types of permeability may well be different and are a subject for further research. As an example, Phung et al. found that, unlike the AVH induced by VEGF-A, the CVH found in mice over-expressing myr-Akt in vascular endothelium was not regulated by eNOS [64].

Finally, just as the angiogenic response induced by VEGF-A differs significantly in different mouse strains [65], it is likely that the permeability response, both basal and that induced by permeability factors, will also differ in mice with different genetic backgrounds, though this has not as yet been investigated in any systematic manner.

\section{Conclusions}

This review has provided a framework for measuring vascular permeability. It has also demonstrated that vascular permeability needs to be considered in at least three distinctly different settings: BVP, AVH and CVH. These distinctions are important as it is likely that both common and different molecular mechanisms are involved in each. Future work will need to focus on the molecular mechanisms by which the molecules in Table 1, and likely others yet to be discovered, act to regulate permeability in each of the three settings.

Acknowledgments This work was supported by NIH grants HL64402 (HFD), CA 109086 (LB), and K01 CA098581 (HZ), by P01 CA92644 (HFD, LB and AMD), by ACS grant RSG-05-118-01-CSM (HZ), and by a contract from the National Foundation for Cancer Research (HFD).

Open Access This article is distributed under the terms of the Creative Commons Attribution Noncommercial License which permits any noncommercial use, distribution, and reproduction in any medium, provided the original author(s) and source are credited.

\section{References}

1. Dvorak H (2007) Tumor blood vessels. Aird, W. Cambridge University Press, New York

2. Dvorak HF (2003) Rous-Whipple award lecture. How tumors make bad blood vessels and stroma. Am J Pathol 162:1747-1757

3. Nagy JA, Dvorak AM, Dvorak HF (2003) VEGF-A(164/165) and PIGF: roles in angiogenesis and arteriogenesis. Trends Cardiovasc Med 13:169-175

4. Nagy JA, Vasile E, Feng D et al (2002) Vascular permeability factor/vascular endothelial growth factor induces lymphangiogenesis as well as angiogenesis. J Exp Med 196:1497-1506

5. Bates DO, Harper SJ (2003) Regulation of vascular permeability by vascular endothelial growth factors. Vascul Pharmacol 39:225-237

6. Carman CV, Sage PT, Sciuto TE et al (2007) Transcellular diapedesis is initiated by invasive podosomes. Immunity 26:784-797

7. Feng D, Nagy JA, Pyne K et al (1998) Neutrophils emigrate from venules by a transendothelial cell pathway in response to FMLP. J Exp Med 187:903-915

8. Hidalgo A, Frenette PS (2007) Leukocyte podosomes sense their way through the endothelium. Immunity 26:753-755

9. Curry FR (2005) Microvascular solute and water transport. Microcirculation 12:17-31

10. Michel CC, Curry FE (1999) Microvascular permeability. Physiol Rev 79:703-761

11. Pappenheimer JR (1953) Passage of molecules through capillary walls. Physiol Rev 33:387-423

12. Guyton A, Hall J (2000) Textbook of medical Physiology. Saunders, Philadelphia

13. Rippe B, Haraldsson B (1994) Transport of macromolecules across microvascular walls: the two-pore theory. Physiol Rev 74:163-219

14. Johnson L (2003) Essential medical physiology. Elsevier Academic Press, Boston 
15. Seifter J, Ratner A, Sloane D (2005) Concepts in medical physiology. Lippincott Williams \& Wilkins, Philadelphia

16. Jain RK (1996) 1995 Whitaker lecture: delivery of molecules, particles, and cells to solid tumors. Ann Biomed Eng 24:457-473

17. Dvorak HF, Orenstein NS, Carvalho AC et al (1979) Induction of a fibrin-gel investment: an early event in line 10 hepatocarcinoma growth mediated by tumor-secreted products. J Immunol 122:166-174

18. Miles AA, Miles EM (1952) Vascular reactions to histamine, histamine-liberator and leukotaxine in the skin of guinea-pigs. J Physiol 118:228-257

19. Senger DR, Galli SJ, Dvorak AM et al (1983) Tumor cells secrete a vascular permeability factor that promotes accumulation of ascites fluid. Science 219:983-985

20. Nagy JA, Feng D, Vasile E et al (2006) Permeability properties of tumor surrogate blood vessels induced by VEGF-A. Lab Invest $86: 767-780$

21. Dvorak HF, Harvey VS, McDonagh J (1984) Quantitation of fibrinogen influx and fibrin deposition and turnover in line 1 and line 10 guinea pig carcinomas. Cancer Res 44:3348-3354

22. Graham MM, Evans ML (1991) A simple, dual tracer method for the measurement of transvascular flux of albumin into the lung. Microvasc Res 42:266-279

23. Albelda SM, Sampson PM, Haselton FR et al (1988) Permeability characteristics of cultured endothelial cell monolayers. J Appl Physiol 64:308-322

24. Cooper JA, Del Vecchio PJ, Minnear FL et al (1987) Measurement of albumin permeability across endothelial monolayers in vitro. J Appl Physiol 62:1076-1083

25. Kevil CG, Payne DK, Mire E et al (1998) Vascular permeability factor/vascular endothelial cell growth factor-mediated permeability occurs through disorganization of endothelial junctional proteins. J Biol Chem 273:15099-15103

26. van Nieuw Amerongen GP, Draijer R, Vermeer MA et al (1998) Transient and prolonged increase in endothelial permeability induced by histamine and thrombin: role of protein kinases, calcium, and RhoA. Circ Res 83:1115-1123

27. Esser S, Wolburg K, Wolburg H et al (1998) Vascular endothelial growth factor induces endothelial fenestrations in vitro. $\mathrm{J}$ Cell Biol 140:947-959

28. Vasile E, Qu H, Dvorak HF et al (1999) Caveolae and vesiculovacuolar organelles in bovine capillary endothelial cells cultured with VPF/VEGF on floating Matrigel-collagen gels. J Histochem Cytochem 47:159-167

29. Dvorak A (2007) Electron microscopic-facilitated understanding of endothelial cell biology: contributions established during the 1950s and 1960s. Aird, W. Cambridge University Press, New York

30. Karnovsky MJ (1967) The ultrastructural basis of capillary permeability studied with peroxidase as a tracer. J Cell Biol 35:213-236

31. Palade G (1960) Transport of quanta across the endothelium of blood capillaries. Anat Rec 136:254

32. Palade G (1988) The microvascular endothelium revisited. In: Simionescu N, Simionescu M (eds) Endothelial cell biology. Plenum Press, New York

33. Palade G, Simionescu M, Simionescu N (1982) Differentiated microdomains in the vascular endothelium. In: Nossel H, Vogel $\mathrm{H}$ (eds) Academic Press, New York

34. Stan R (2007) Endothelial structures involved in vascular permeability. Aird, W. Cambridge University Press, New York

35. Rosengren BI, Rippe A, Rippe C et al (2006) Transvascular protein transport in mice lacking endothelial caveolae. Am J Physiol Heart Circ Physiol 291:H1371-1377

36. Schubert W, Frank PG, Woodman SE et al (2002) Microvascular hyperpermeability in caveolin-1 (-/-) knock-out mice. Treat- ment with a specific nitric-oxide synthase inhibitor, L-NAME, restores normal microvascular permeability in Cav-1 null mice. $\mathrm{J}$ Biol Chem 277:40091-40098

37. Boesiger J, Tsai M, Maurer M et al (1998) Mast cells can secrete vascular permeability factor/vascular endothelial cell growth factor and exhibit enhanced release after immunoglobulin Edependent upregulation of fc epsilon receptor I expression. J Exp Med 188:1135-1145

38. Galli SJ (2000) Mast cells and basophils. Curr Opin Hematol 7:32-39

39. Galli SJ (1997) The Paul Kallos Memorial Lecture. The mast cell: a versatile effector cell for a challenging world. Int Arch Allergy Immunol 113:14-22

40. Dvorak HF, Quay SC, Orenstein NS et al (1981) Tumor shedding and coagulation. Science 212:923-924

41. VanDeWater L, Tracy PB, Aronson D et al (1985) Tumor cell generation of thrombin via functional prothrombinase assembly. Cancer Res 45:5521-5525

42. Majno G, Palade GE, Schoefl GI (1961) Studies on inflammation. II. The site of action of histamine and serotonin along the vascular tree: a topographic study. J Biophys Biochem Cytol 11:607-626

43. Majno G, Shea SM, Leventhal M (1969) Endothelial contraction induced by histamine-type mediators: an electron microscopic study. J Cell Biol 42:647-672

44. Kohn S, Nagy JA, Dvorak HF et al (1992) Pathways of macromolecular tracer transport across venules and small veins. Structural basis for the hyperpermeability of tumor blood vessels. Lab Invest 67:596-607

45. Dvorak AM, Kohn S, Morgan ES et al (1996) The vesiculovacuolar organelle (VVO): a distinct endothelial cell structure that provides a transcellular pathway for macromolecular extravasation. J Leukoc Biol 59:100-115

46. Feng D, Nagy J, Dvorak A et al (2000) Different pathways of macromolecule extravasation from hyperpermeable tumor vessels. Microvascular Research 59:24-37

47. Feng D, Nagy JA, Hipp J et al (1996) Vesiculo-vacuolar organelles and the regulation of venule permeability to macromolecules by vascular permeability factor, histamine, and serotonin. J Exp Med 183:1981-1986

48. Feng D, Nagy JA, Hipp J et al (1997) Reinterpretation of endothelial cell gaps induced by vasoactive mediators in guinea-pig, mouse and rat: many are transcellular pores. J Physiol 504(Pt 3):747-761

49. Feng D, Nagy JA, Pyne K et al (1999) Pathways of macromolecular extravasation across microvascular endothelium in response to VPF/VEGF and other vasoactive mediators. Microcirculation 6:23-44

50. Neal CR, Michel CC (1995) Transcellular gaps in microvascular walls of frog and rat when permeability is increased by perfusion with the ionophore A23187. J Physiol 488(Pt 2):427-437

51. Nagy JA, Masse EM, Herzberg KT et al (1995) Pathogenesis of ascites tumor growth: vascular permeability factor, vascular hyperpermeability, and ascites fluid accumulation. Cancer Res 55:360-368

52. Jain RK (1988) Determinants of tumor blood flow: a review. Cancer Res 48:2641-2658

53. Pettersson A, Nagy JA, Brown LF et al (2000) Heterogeneity of the angiogenic response induced in different normal adult tissues by vascular permeability factor/vascular endothelial growth factor. Lab Invest 80:99-115

54. Sundberg C, Nagy JA, Brown LF et al (2001) Glomeruloid microvascular proliferation follows adenoviral vascular permeability factor/vascular endothelial growth factor-164 gene delivery. Am J Pathol 158:1145-1160 
55. Brown LF, Detmar M, Claffey K et al (1997) Vascular permeability factor/vascular endothelial growth factor: a multifunctional angiogenic cytokine. Exs 79:233-269

56. Brown LF, Yeo KT, Berse B et al (1992) Expression of vascular permeability factor (vascular endothelial growth factor) by epidermal keratinocytes during wound healing. J Exp Med 176:1375-1379

57. Ren G, Michael LH, Entman ML et al (2002) Morphological characteristics of the microvasculature in healing myocardial infarcts. J Histochem Cytochem 50:71-79

58. Dvorak HF, Rickles FR (2005) Hemostasis and thrombosis in cancer. In: Colman RW, Hirsh J, Marder VJ, Clowes AW, George JN (eds) Homeostasis and thrombosis. Lippincott Williams \& Wilkins, Philadelphia

59. Dvorak HF, Dvorak AM, Manseau EJ et al (1979) Fibrin gel investment associated with line 1 and line 10 solid tumor growth, angiogenesis, and fibroplasia in guinea pigs. Role of cellular immunity, myofibroblasts, microvascular damage, and infarction in line 1 tumor regression. J Natl Cancer Inst 62:1459-1472

60. Roberts WG, Palade GE (1995) Increased microvascular permeability and endothelial fenestration induced by vascular endothelial growth factor. J Cell Sci 108(Pt 6):2369-2379

61. Dejana E (2004) Endothelial cell-cell junctions: happy together. Nat Rev Mol Cell Biol 5:261-270

62. Oh P, Borgstrom P, Witkiewicz H et al (2007) Live dynamic imaging of caveolae pumping targeted antibody rapidly and specifically across endothelium in the lung. Nat Biotechnol $25: 327-337$

63. Ioannidou S, Deinhardt K, Miotla J et al (2006) An in vitro assay reveals a role for the diaphragm protein PV-1 in endothelial fenestra morphogenesis. Proc Natl Acad Sci U S A 103:1677016775

64. Phung TL, Ziv K, Dabydeen D et al (2006) Pathological angiogenesis is induced by sustained Akt signaling and inhibited by rapamycin. Cancer Cell 10:159-170

65. Rohan RM, Fernandez A, Udagawa T et al (2000) Genetic heterogeneity of angiogenesis in mice. Faseb J 14:871-876

66. Predescu D, Predescu S, Shimizu J et al (2005) Constitutive eNOS-derived nitric oxide is a determinant of endothelial junctional integrity. Am J Physiol Lung Cell Mol Physiol 289:L371L381

67. Sun JF, Phung T, Shiojima I et al (2005) Microvascular patterning is controlled by fine-tuning the Akt signal. Proc Natl Acad Sci U S A 102:128-133

68. Odorisio T, Schietroma C, Zaccaria ML et al (2002) Mice overexpressing placenta growth factor exhibit increased vascularization and vessel permeability. J Cell Sci 115:2559-2567

69. Thurston G, Suri C, Smith K et al (1999) Leakage-resistant blood vessels in mice transgenically overexpressing angiopoietin-1. Science 286:2511-2514

70. Larcher F, Murillas R, Bolontrade M et al (1998) VEGF/VPF overexpression in skin of transgenic mice induces angiogenesis, vascular hyperpermeability and accelerated tumor development. Oncogene 17:303-311

71. Moulton KS, Olsen BR, Sonn S et al (2004) Loss of collagen XVIII enhances neovascularization and vascular permeability in atherosclerosis. Circulation 110:1330-1336

72. Hatakeyama T, Pappas PJ, Hobson RW II et al (2006) Endothelial nitric oxide synthase regulates microvascular hyperpermeability in vivo. J Physiol 574:275-281

73. Ackah E, Yu J, Zoellner S et al (2005) Akt1/protein kinase Balpha is critical for ischemic and VEGF-mediated angiogenesis. J Clin Invest 115:2119-2127

74. Chen J, Somanath PR, Razorenova O et al (2005) Akt1 regulates pathological angiogenesis, vascular maturation and permeability in vivo. Nat Med 11:1188-1196
75. Streit M, Velasco P, Riccardi L et al (2000) Thrombospondin-1 suppresses wound healing and granulation tissue formation in the skin of transgenic mice. Embo J 19:3272-3282

76. Lange-Asschenfeldt B, Weninger W, Velasco P et al (2002) Increased and prolonged inflammation and angiogenesis in delayed-type hypersensitivity reactions elicited in the skin of thrombospondin-2-deficient mice. Blood 99:538-545

77. Robinson SD, Reynolds LE, Wyder L et al (2004) Beta3-integrin regulates vascular endothelial growth factor-A-dependent permeability. Arterioscler Thromb Vasc Biol 24:2108-2114

78. Elson DA, Thurston G, Huang LE et al (2001) Induction of hypervascularity without leakage or inflammation in transgenic mice overexpressing hypoxia-inducible factor-1alpha. Genes Dev $15: 2520-2532$

79. Fukumura D, Gohongi T, Kadambi A et al (2001) Predominant role of endothelial nitric oxide synthase in vascular endothelial growth factor-induced angiogenesis and vascular permeability. Proc Natl Acad Sci U S A 98:2604-2609

80. Bauer PM, Yu J, Chen Y et al (2005) Endothelial-specific expression of caveolin-1 impairs microvascular permeability and angiogenesis. Proc Natl Acad Sci U S A 102:204-209

81. Eliceiri BP, Paul R, Schwartzberg PL et al (1999) Selective requirement for Src kinases during VEGF-induced angiogenesis and vascular permeability. Mol Cell 4:915-924

82. Sano H, Hosokawa $\mathrm{K}$, Kidoya $\mathrm{H}$ et al (2006) Negative regulation of VEGF-induced vascular leakage by blockade of angiotensin II type 1 receptor. Arterioscler Thromb Vasc Biol 26:2673-2680

83. Carmeliet P, Moons L, Luttun A et al (2001) Synergism between vascular endothelial growth factor and placental growth factor contributes to angiogenesis and plasma extravasation in pathological conditions. Nat Med 7:575-583

84. Luttun A, Brusselmans K, Fukao H et al (2002) Loss of placental growth factor protects mice against vascular permeability in pathological conditions. Biochem Biophys Res Commun 295:428-434

85. Mamluk R, Klagsbrun M, Detmar M et al (2005) Soluble neuropilin targeted to the skin inhibits vascular permeability. Angiogenesis 8:217-227

86. Wegmann F, Petri B, Khandoga AG et al (2006) ESAM supports neutrophil extravasation, activation of Rho, and VEGF-induced vascular permeability. J Exp Med 203:1671-1677

87. Su G, Hodnett M, Wu N et al (2007) Integrin alphavbeta5 regulates lung vascular permeability and pulmonary endothelial barrier function. Am J Respir Cell Mol Biol 36:377-386

88. Sonveaux P, Martinive P, DeWever J et al (2004) Caveolin-1 expression is critical for vascular endothelial growth factorinduced ischemic hindlimb collateralization and nitric oxidemediated angiogenesis. Circ Res 95:154-161

89. Woodman SE, Ashton AW, Schubert W et al (2003) Caveolin-1 knockout mice show an impaired angiogenic response to exogenous stimuli. Am J Pathol 162:2059-2068

90. Reynolds LE, Wyder L, Lively JC et al (2002) Enhanced pathological angiogenesis in mice lacking beta 3 integrin or beta 3 and beta5 integrins. Nat Med 8:27-34

91. Dewever J, Frerart F, Bouzin C et al (2007) Caveolin-1 Is critical for the maturation of tumor blood vessels through the regulation of both endothelial tube formation and mural cell recruitment. Am J Pathol 171:1619-1628.

92. Lin MI, Yu J, Murata T et al (2007) Caveolin-1-deficient mice have increased tumor microvascular permeability, angiogenesis, and growth. Cancer Res 67:2849-2856

93. Dvorak HF, Nagy JA, Feng D et al (1999) Vascular permeability factor/vascular endothelial growth factor and the significance of microvascular hyperpermeability in angiogenesis. Curr Top Microbiol Immunol 237:97-132 